\title{
Influence of MEA and piperazine additives on the desulfurization ability of MDEA aqueous for natural gas purification
}

\author{
Shi Yunhai ${ }^{1} \cdot$ Liang Shan $^{1} \cdot$ Li Wei $^{1} \cdot$ Luo Dong $^{2} \cdot$ Gatabazi Remy $^{1} \cdot$ \\ Du JianPeng ${ }^{1}$
}

Received: 25 August 2015/Accepted: 19 January 2016/Published online: 12 February 2016

(c) The Author(s) 2016. This article is published with open access at Springerlink.com

\begin{abstract}
The influence of monoethanolamine (MEA) and piperazine added into methyldiethanolamine (MDEA) aqueous solution on the desulfurization of natural gas was investigated by the method of equilibrium data determination in this paper. Four kinds of equilibrated systems, i.e. $\mathrm{H}_{2} \mathrm{~S}-\mathrm{NG}$-MEA-water, $\mathrm{H}_{2} \mathrm{~S}$-NG-MDEA-water, $\mathrm{H}_{2} \mathrm{~S}-\mathrm{NG}$ (MEA-MDEA)-water, $\mathrm{H}_{2} \mathrm{~S}$ - NG-(MEA-MDEA-PZ)-water at the temperature ranging from 298.15 to $333.15 \mathrm{~K}$ were measured in a glass-jacketed gas absorption cell with a double-drive impeller device. The results show that the $\mathrm{H}_{2} \mathrm{~S}$ partial pressure increases with the increase of $\mathrm{H}_{2} \mathrm{~S}$ loading in liquid phase along an isotherm. The addition of MEA and PZ is beneficial for improving the desulfuration ability of MDEA. The ability of $\mathrm{H}_{2} \mathrm{~S}$ absorption for the four mixed alkanolamine systems is MEA $>$ (MEA-MDEAPZ) $>$ (MEA-MDEA) $>$ MDEA according to the order of size. The four equilibrium data can be well correlated with the Soave-Redlich-Kwong equation of state and electrolyte-NRTL activity coefficient model. The overall mean relative errors of total pressure and $\mathrm{H}_{2} \mathrm{~S}$ partial pressure between the calculated and experimental data of the four systems are 3.30 and $3.07 \%$, respectively. The experimental and calculated results are very useful for desulfuration and purification process of natural gas or other industrial gases.
\end{abstract}

Shi Yunhai

shi_yunhai@sina.com; shi_yunhai@ecust.edu.cn;

shi_yunhai@hotmail.com

1 Research Centre of Chemical Engineering, East China University of Science and Technology, 130 Meilong Road, Box 368, Shanghai 200237, China

2 Chongqing General Gas Purification Plant, Southwest Oil and Gas Field Branch Company, 44 Taohua Road, Chongqing 401220, China
Keywords Desulfuration · Hydrogen sulfide - Natural gas · Monoethanolamine - Methyldiethanolamine ·

Piperazine

\section{List of symbols}

\begin{tabular}{|c|c|}
\hline \multicolumn{2}{|c|}{ Variables } \\
\hline wt. & Abbreviation of weight \\
\hline vol. & Abbreviation of volume \\
\hline NG & Abbreviation of natural gas \\
\hline MEA & Abbreviation of monoethanolamine \\
\hline MDEA & Abbreviation of methyldiethanolamine \\
\hline PZ & Abbreviation of piperazine \\
\hline$n_{\text {amines }}$ & $\begin{array}{l}\text { The total mole numbers of } \\
(\mathrm{MEA}+\mathrm{MDEA}+\mathrm{PZ}), \text { mol }\end{array}$ \\
\hline$L$ & $\mathrm{H}_{2} \mathrm{~S}$ loading in liquid phase, $\mathrm{mol} / \mathrm{mol}$ \\
\hline$n$ & The mole number of each species, mol \\
\hline$V_{\mathrm{I}_{2}}$ & $\begin{array}{l}\text { The volume of } \mathrm{I}_{2} \text { standard solution } \\
\text { consumed with titration, } \mathrm{mL}\end{array}$ \\
\hline$c_{\mathrm{I}_{2}}$ & $\begin{array}{l}\text { The concentration of } \mathrm{I}_{2} \text { standard solution, } \\
\mathrm{mol} / \mathrm{L}\end{array}$ \\
\hline$R$ & Universal gas constant, $8.3145 \mathrm{~J} /(\mathrm{mol} \mathrm{K})$ \\
\hline$m$ & Weight of MEA, MDEA and PZ, g \\
\hline$V$ & Volume of gas sample, $\mathrm{m}^{3}$ \\
\hline$p_{a}$ & Atmosphere pressure, $\mathrm{kPa}$ \\
\hline$\Delta h$ & $\begin{array}{l}\text { Reading difference of the glass U-tube } \\
\text { manometer, } \mathrm{kPa}\end{array}$ \\
\hline$p$ & The equilibrium total pressure, $\mathrm{kPa}$ \\
\hline$p_{\text {read }}$ & Fortin Barometer reading, $\mathrm{kPa}$ \\
\hline$t$ & Room temperature when testing, ${ }^{\circ} \mathrm{C}$ \\
\hline$M$ & Molecular weight, g/mol \\
\hline$N$ & Number of experimental points \\
\hline$H$ & Henry's constant of Eqs. 15, 16 and 18 \\
\hline
\end{tabular}


$p_{\text {exp }}, p_{\text {lit }} \quad$ Experimental and literature data of $\mathrm{H}_{2} \mathrm{~S}$ partial pressure, $\mathrm{kPa}$

$T \quad$ Absolute temperature, $\mathrm{K}$

$K \quad$ Equilibrium constants for $R 1-R 6$

$a_{i} \quad$ Activity of component $i$

$z_{i} \quad$ Valency of an ion $i$

$x \quad$ Liquid phase mole fraction

$y \quad$ Gas phase mole fraction

$A_{1}, A_{2}, A_{3}, A_{4} \quad$ Parameters of Eq. 15

$\mathrm{D} \quad$ Dielectric constants

$A, B \quad$ Parameters in Table 4

$a, b \quad$ Parameters of Eq. 18

$T_{\mathrm{c}} \quad$ Critical temperature, $\mathrm{K}$

$p_{\mathrm{c}} \quad$ Critical pressure, $\mathrm{kPa}$

$V_{\mathrm{c}} \quad$ Critical volume, $\mathrm{m}^{3} / \mathrm{kmol}$

$Z_{\mathrm{c}} \quad$ Critical compressibility factor

\section{Subscripts}

I Component $i$

$J \quad$ W, 1, 2, 3, 4, 5

exp. Experimental

lit. Literature

cal. Calculated

\section{Superscipts}

$\infty \quad$ Infinite dilution in pure water

$\varnothing \quad$ Reference state, standard state

\section{Greek alphabet}

$\omega$ Parameter of Eq. 18

$v_{i} \quad$ Stoichiometric coefficient of component $i$

$\gamma_{i} \quad$ Activity coefficient of component $i$

$\hat{\varphi}_{i} \quad$ Fugacity coefficient of component $i$ in a mixture

\section{Introduction}

The desulfuration of natural gas (NG), and the gas streams in petroleum refinery and chemical plant is of a great importance concerning energy efficiency and environment safety. The main method for these industries is the absorption of acid gases (mainly $\mathrm{CO}_{2}$ and $\mathrm{H}_{2} \mathrm{~S}$ ) by using aqueous alkanolamine solutions followed by the desorption from solutions by using steam stripping [1]. The monoethanolamine (MEA), methyldiethanolamine (MDEA) and their blends are the commonly used absorbents, and piperazine is often widely used as an additive.

MEA is the common gas treating alkanolamine solvent due to its high reactivity, low cost, ease of reclamation, and low solubility of hydrocarbons. The disadvantage of MEA is the large enthalpy of reaction with carbon dioxide, as well as the formation of stable carbamate which limits its absorption capability [2]. MDEA is difficult to react directly with $\mathrm{CO}_{2}$ to form carbamate. That is to say, the selectivity of MDEA absorption for $\mathrm{H}_{2} \mathrm{~S}$ is higher than that of MEA when $\mathrm{H}_{2} \mathrm{~S}$ and $\mathrm{CO}_{2}$ are both present. Moreover, the regeneration cost for MDEA is lower than that of MEA [3]. A kind of solvent with aqueous blend alkanolamine by adding an additive is widely used to enhance the loading of acid gas. Piperazine is most commonly used as a chemical activator. It is reported that $\mathrm{PZ}$ is more effective than the other conventional activators. The major advantages of PZ are its high reaction rate, and high resistance of thermal and oxidative degradation. Besides, the blends of PZ and amines exhibit low amine volatility due to the non-ideality of the mixed amine solution [4, 5]. The advantages and disadvantages of MEA, MDEA and PZ have been summarized in literatures [6-10].

The gas-liquid equilibria data of $\mathrm{H}_{2} \mathrm{~S}$ in the aqueous MEA, MDEA and the blends of MEA and MDEA solution are reported in a lot of literatures with different concentration, temperature, $\mathrm{H}_{2} \mathrm{~S}$ loading and partial pressure. Lee et al. [11] measured the gas-liquid equilibrium of $\mathrm{H}_{2} \mathrm{~S}-\mathrm{MEA}-\mathrm{H}_{2} \mathrm{O}$ system under the conditions of MEA concentration from 2.5 to $5.0 \mathrm{~N}$, temperature at $298.15,313.15,333.15,353.15$, 373.15 and $393.15 \mathrm{~K}$, and the $\mathrm{H}_{2} \mathrm{~S}$ partial pressure from 0.15 to $2317 \mathrm{kPa}$. Isaacs et al. [12] reported the solubilities of $\mathrm{H}_{2} \mathrm{~S}, \mathrm{CO}_{2}$ and their mixture in the $2.5 \mathrm{~mol} / \mathrm{L}$ aqueous solution of MEA at $373.15 \mathrm{~K}$ and acid gases partial pressure from $0.03 \mathrm{kPa}$ to $3.36 \mathrm{kPa}$. Jou et al. [13] determined the solubilities of $\mathrm{H}_{2} \mathrm{~S}$ and $\mathrm{CO}_{2}$ dissolved in the aqueous MDEA solution under the conditions of temperature from 313.15 to $393.15 \mathrm{~K}$ and partial pressure of acid gas up to $6600 \mathrm{kPa}$. The experimental data were correlated with the procedure presented by Kent and Eisenberg. They [14, 15] also measured the solubilities of $\mathrm{H}_{2} \mathrm{~S}, \mathrm{CO}_{2}$, and $\mathrm{H}_{2} \mathrm{~S}+\mathrm{CO}_{2}$ in $35 \%$ wt. aqueous MDEA solution at temperature from 313.15 to $373.15 \mathrm{~K}$, and the experimental data were regressed by the Deshmukh-Mather correlation. Kuranov et al. [16] investigated the solubilities of single gas $\mathrm{CO}_{2}$ and $\mathrm{H}_{2} \mathrm{~S}$ in the aqueous MDEA solution under the conditions of temperature from 313.15 to $413.15 \mathrm{~K}$, and the total pressure up to $5 \mathrm{MPa}$. A mathematical model of taking into account contributions of chemical reaction and physical interaction was prosposed to correlate the experimental data. Kamps [17] reported the experimental data of solubilities of $\mathrm{CO}_{2}$ and $\mathrm{H}_{2} \mathrm{~S}$ in $8 \mathrm{~mol} / \mathrm{kg}$ aqueous MDEA solution under the conditions of temperature from 313.15 to $393.15 \mathrm{~K}$, and the total pressure up to 7.6 MPa. Li et al. [18] investigated solubilities of $\mathrm{H}_{2} \mathrm{~S}$ in aqueous MEA and MDEA blend under the conditions of temperatures from 313.15 to $373.15 \mathrm{~K}$, and at $\mathrm{H}_{2} \mathrm{~S}$ partial pressure up to $450 \mathrm{kPa}$.

Unlike the previous works, the NG was introduced as a makeup gas herein to actualize the industrial desulfuration process of natural gas, and the gas-liquid equilibrium of aqueous $\mathrm{H}_{2} \mathrm{~S}$-(MEA-MDEA-PZ)-water solution was determined experimentally in this work. The gas-liquid 
equilibria data of the four systems of $\mathrm{H}_{2} \mathrm{~S}-\mathrm{NG}-\mathrm{MEA}$-water, $\mathrm{H}_{2} \mathrm{~S}$-NG-MDEA-water, $\quad \mathrm{H}_{2} \mathrm{~S}-\mathrm{NG}$-(MEA-MDEA)-water and $\mathrm{H}_{2} \mathrm{~S}-\mathrm{NG}$-(MEA-MDEA-PZ)-water were measured in a homemade equilibrium apparatus under the conditions of the temperature from 298.15 to $333.15 \mathrm{~K}$, and the $\mathrm{H}_{2} \mathrm{~S}$ partial pressure up to $60 \mathrm{kPa}$. And a thermodynamic model was used to correlate the experimental data.

\section{Experimental section}

\section{Reagents and materials}

Monoethanolamine (MEA, $\geq 99.0 \%$ wt.), methyldiethanolamine (MDEA, $\geq 99.0 \%$ wt.), piperazine (PZ, $\geq 99.0 \%$ wt. $)$, sodium thiosulfate $\left(\mathrm{Na}_{2} \mathrm{~S}_{2} \mathrm{O}_{3}, \geq 99.0 \%\right.$ wt. $)$, soluble starch, kalium iodide (KI, $\geq 98.5 \%$ wt.) and sodium sulfide $\left(\mathrm{Na}_{2} \mathrm{~S}, \geq 98.0 \%\right.$ wt.) were purchased from Shanghai Ling Feng Chemical Reagent Co., Ltd., China. Iodine $\left(\mathrm{I}_{2}\right.$, $\geq 99.8 \%$ wt.) was bought from Zhejiang Lingfu fine chemicals plant, China. Sulfuric aicd $\left(\mathrm{H}_{2} \mathrm{SO}_{4}, \geq 98.0 \%\right.$ wt.) and hydrochloric acid ( $\mathrm{HCl}, \geq 36 \%$ wt.) were bought from Jiangsu Yonghua Fine Chemicals Co., Ltd., China. Zinc acetate $\left[\mathrm{Zn}\left(\mathrm{CH}_{3} \mathrm{COO}\right)_{2}\right.$, $\geq 99 \%$ wt.] was supplied by Sinopharm Chemical Reagent Co., Ltd., China.

The natural gas in this work was obtained from laboratory natural gas pipeline which consists of $96.266 \% \mathrm{CH}_{4}$ (vol, the same below), $1.770 \% \quad \mathrm{C}_{2} \mathrm{H}_{6}, 0.300 \% \mathrm{C}_{3} \mathrm{H}_{8}$, $0.062 \% \quad i-\mathrm{C}_{4} \mathrm{H}_{10}, 0.075 \% n-\mathrm{C}_{4} \mathrm{H}_{10}, 0.125 \% \mathrm{C}_{5} \mathrm{H}_{12}$ and $1.442 \% \mathrm{~N}_{2}$.

\section{Apparatus and experimental method}

A static-analytic method was used to measure the gasliquid equilibrium data of these systems stated above, and the experimental apparatus is shown in Fig. 1.

The apparatus in Fig. 1 consists of three parts. The first is a $\mathrm{H}_{2} \mathrm{~S}$ generator. The second one is an equilibrium cell, and the third one is the measurements of equilibrium temperature and pressure, as well as the samplings.

The $\mathrm{H}_{2} \mathrm{~S}$ generator is composed of a dropping funnel (1) containing $1 \mathrm{~mol} / \mathrm{L}$ aqueous $\mathrm{H}_{2} \mathrm{SO}_{4}$ solution and the $\mathrm{H}_{2} \mathrm{~S}$ generator vessel (2) with $10 \%$ wt. $\mathrm{Na}_{2} \mathrm{~S}$ solution. The equilibrium cell (9) is a glass-jacketed gas liquid absorber with two double drive impellers. The rotating speeds of the gas phase impeller (10-2) and liquid phase impeller (10-1) are controlled by its own direct current motor (12-1), (122 ), respectively. And the speed is displayed on the screen of revolution counter. The absorption temperature is measured by a mercurial thermometer (8) with a sensitivity of $0.1{ }^{\circ} \mathrm{C}$, which is adjusted by the constant temperature circulating water (14), (15) with a water thermostat. The pressure difference was determined by a glass U-tube manometer (18) with the minimum resolution of $0.1 \mathrm{mmHg}(0.013 \mathrm{kPa})$. The absorption pressure equates the pressure difference plus the atmosphere pressure measured by a Fortin Barometer. Liquid sampling is undertaken with a $2 \mathrm{~mL}$ injection syringe connected with the liquid sampling valve (11), and analyzed by the methods of weighing and chemical iodine titration. Gas sampling is done quantitatively with a eudiometer (16).

Operation procedures The absorption alkanolamines agent is firstly added into the equilibrium cell (9) from the leveling bottle (5) and valve (6). Then the whole absorption unit including the pipelines is vacuumized and degassed by a vacuum air pump (21). Afterward the stopcock of dropping funnel (1) is opened and then let the aqueous sulfuric acid reacts with sodium sulfide to generate hydrogen sulfide. The gas of hydrogen sulfide is mixed with NG derived from the pipeline and its valve (4). The gas mixture is introduced into the equilibrium cell (9) and absorbed by the alkanolamines agent under a specified pressure and temperature. The system could be thought to reach the equilibration when the absorption time is about $1-1.5 \mathrm{~h}$ by preliminary test.

Analysis method The method of iodine quantity is used for determining the content of hydrogen sulfide in the liquid phase. About $1 \mathrm{~mL}$ liquid sample drawn from the equilibrium cell with a $2 \mathrm{~mL}$ injection syringe, and weighted by an electric analytical balance with accuracy of $0.0001 \mathrm{~g}$. Then it is slowly injected underneath the liquid interface of a $250 \mathrm{~mL}$ volumetric flask containing $25 \mathrm{~mL}$ aqueous $0.1 \mathrm{~mol} / \mathrm{L}$ zinc acetate. The injection syringe is washed with this aqueous zinc acetate for three times, and for another two times washed with pure water. All of the cleaning water should be collected and mixed with the aqueous zinc acetate. Afterwards, the $\mathrm{pH}$ value of the aqueous solution is adjusted to $6.5 \sim 7.0$ with $0.01 \mathrm{~mol} / \mathrm{L}$ $\mathrm{HCl}$ solution. Add appropriate amount of iodine standard solution into the liquid, sealed and preserved under a dark place for at least $5 \mathrm{~min}$. The mixture is titrated with $0.01 \mathrm{~mol} / \mathrm{L}$ sodium thiosulfate standard solution to the color of buff; successively by added starch indicator, continuing titrated with the sodium thiosulfate standard solution to the color of blue disappearing as the titration end point [19]. The reactions included in this procedure can be written as from Eqs. (1-3).

$$
\begin{aligned}
& \mathrm{H}_{2} \mathrm{~S}+\mathrm{Zn}\left(\mathrm{CH}_{3} \mathrm{COO}\right)_{2} \rightarrow \mathrm{ZnS}+2 \mathrm{CH}_{3} \mathrm{COOH} \\
& \mathrm{ZnS}+2 \mathrm{HCl}+\mathrm{I}_{2} \rightarrow \mathrm{ZnCl}_{2}+\mathrm{S}+2 \mathrm{HI} \\
& \mathrm{I}_{2}+2 \mathrm{Na}_{2} \mathrm{~S}_{2} \mathrm{O}_{3} \rightarrow 2 \mathrm{NaI}+\mathrm{Na}_{2} \mathrm{~S}_{4} \mathrm{O}_{6}
\end{aligned}
$$

$L$ value represents the molar loading quantity of hydrogen sulfide per molar alkanolamines in liquid aqueous solution, which reflects the absorption ability of absorbents for $\mathrm{H}_{2} \mathrm{~S}$. It is calculated as 


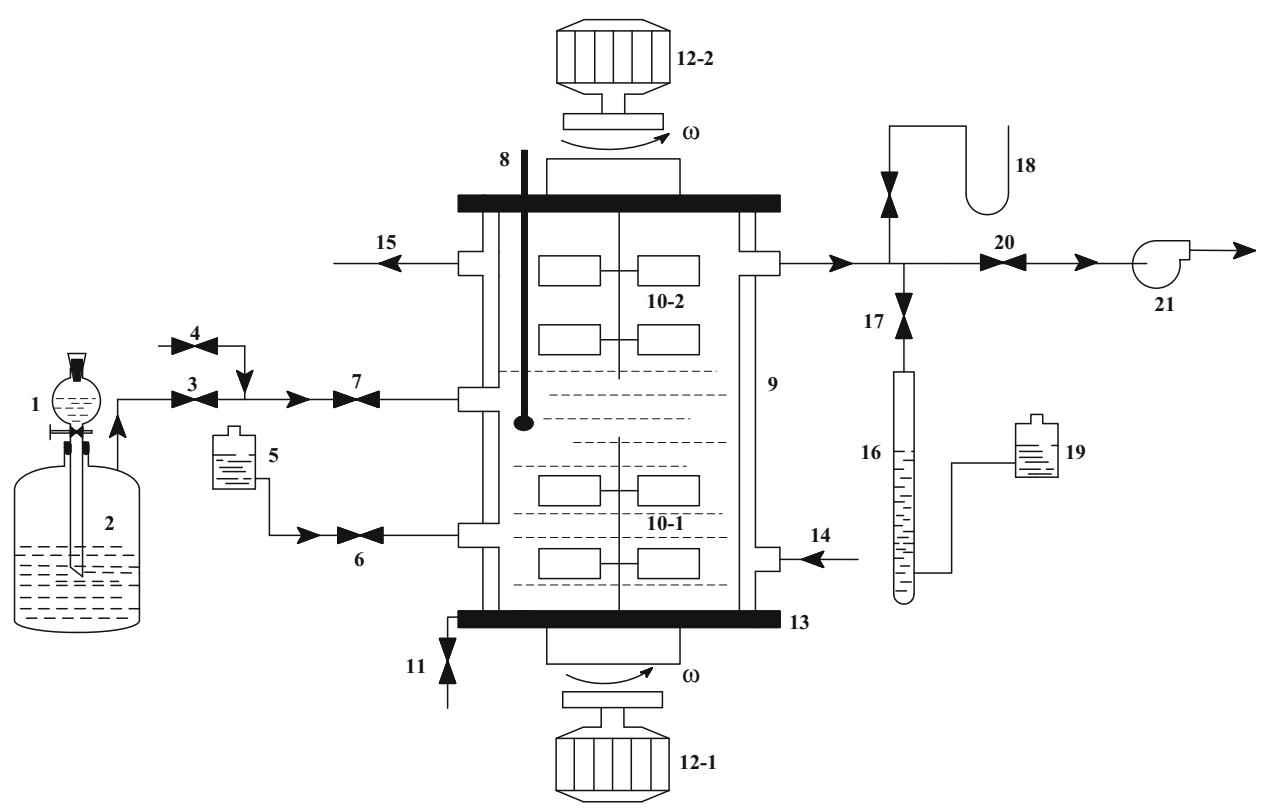

Fig. 1 Flow chart of the measurement equipment for gas-liquid equilibria 1 dropping funnel containing $\mathrm{H}_{2} \mathrm{SO}_{4}, 2 \mathrm{H}_{2} \mathrm{~S}$ generator vessel, $3 \mathrm{H}_{2} \mathrm{~S}$ outlet valve, $4 \mathrm{NG}$ inlet pipeline, 5 leveling bottle, 6 alkanolamines inlet pipeline and valve, $7 \mathrm{H}_{2} \mathrm{~S}$ and $\mathrm{NG}$ mixture inlet valve, 8 mercurial thermometer, 9 glass-jacketed equilibrium cell, (10-1, 10-2) electromagnet driving double agitator blades, 11 liquid

$$
\begin{aligned}
& L\left(\text { mol } \mathrm{H}_{2} \mathrm{~S} / \text { mol amine }\right)=\frac{n_{\mathrm{H}_{2} \mathrm{~S}}}{n_{\text {amines }}} \\
& =\frac{\left(V_{\mathrm{I}_{2}} c_{\mathrm{I}_{2}}-V_{\mathrm{Na}_{2} \mathrm{~S}_{2} \mathrm{O}_{3}} c_{\mathrm{Na}_{2} \mathrm{~S}_{2} \mathrm{O}_{3}}\right) \times 0.5 \times 10^{-3}}{n_{\text {amines }}}
\end{aligned}
$$

where $V_{\mathrm{I}_{2}}, c_{\mathrm{I}_{2}}$ are the volume consumed and molar con-

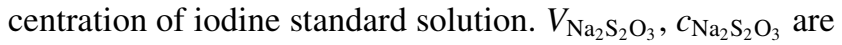
the volume titration demanded and molar concentration of sodium thiosulfate standard solution. $n_{\text {amines }}$ is molar quantity of the mixed alkanolamines calculated by:

$n_{\mathrm{amines}}=\frac{m_{\mathrm{MEA}}}{M_{\mathrm{MEA}}}+\frac{m_{\mathrm{MDEA}}}{M_{\mathrm{MDEA}}}+\frac{m_{\mathrm{PZ}}}{M_{\mathrm{PZ}}}$

In Eq. (5), $m_{i}$ and $M_{i}$ are the quality and molecular weight of the mixed alkanolamines component $i$.

The analysis method of gas phase: Firstly, $50 \mathrm{~mL}$ $0.1 \mathrm{~mol} / \mathrm{L}$ zinc acetate solution is added into the leveling bottle (19). Keep the liquid interface of eudiometer (16) and leveling bottle (19), and record the initial scale value. Open the gas sampling valve (17) and let the gas phase into the eudiometer, then close the sampling valve and record the end reading. The difference of the ending and the initial readings is the gas sampling volume. Shake the eudiometer and let the sampling gas mix completely with the solution of zinc acetate. The reaction liquid is transferred to a clean $250 \mathrm{~mL}$ volumetric flask. Washing the eudiometer with sampling valve, $(12-1,12-2)$-direct current motor, 13 two pieces of stainless steel flange, 14 constant temperature circulating water inlet, 15 constant temperature circulating water outlet, 16 eudiometer, 17 gas sampling valve, 18 glass U-tube manometer, 19 leveling bottle, 20 vacuum pump valve, 21 vacuum air pump

pure water two times, and the washed water is also added into the volumetric flask. Afterwards, an adequate quantity of iodine standard solution is added, and then sealed and preserved under a dark place for at least $5 \mathrm{~min}$. Then, titration of sodium thiosulfate is adopted as described above for analyzing the containing of hydrogen sulfide. The Eq. (6) is used for calculation the molar fraction of hydrogen sulfide in the gas phase.

$y_{\mathrm{H}_{2} \mathrm{~S}}=\frac{\left(V_{\mathrm{I}_{2}} c_{\mathrm{I}_{2}}-V_{\mathrm{Na}_{2} \mathrm{~S}_{2} \mathrm{O}_{3}} c_{\mathrm{Na}_{2} \mathrm{~S}_{2} \mathrm{O}_{3}}\right) \times 0.5 R T}{p V}$

In Eq. (6), $T$ and $V$ are the equilibrium temperature and volume of the sampling gas phase. $R$ is the universal gas constant, $8.3145 \mathrm{~J} /(\mathrm{mol} \mathrm{K}) . \quad p$ is the equilibrium total pressure, and calculated as

$p=p_{a}+\Delta h$

where $\Delta h$ is the reading difference of the glass U-tube manometer (18), $p_{a}$ is the atmosphere pressure measured by a Fortin Barometer. For Shanghai, it is calculated as

$p_{a}=0.9988 p_{\text {read }}\left(1-\frac{1.634 \times 10^{-4} t}{1+1.818 \times 10^{-4} t} \times t\right)$

In the Eq. (8), $p_{\text {read }}$ is the reading value of the Fortin Barometer, and $t$ is the room temperature during the experiments. 


\section{The reliability of the apparatus}

In order to check the reliability of the apparatus and experimental method, gas-liquid equilibrium data of hydrogen sulfide dissolved in $2.5 \mathrm{~mol} / \mathrm{L}$ MEA aqueous solution under $313.15 \mathrm{~K}$ and atmosphere pressure were measured and compared with the literature data [11]. The results are shown in Fig. 2.

The results shown in Fig. 2 indicate that the experimental value is agreed very well with the literature data, and the maximum relative error is less than $5 \%$. It shows that the apparatus is suitable for determination the gasliquid equilibrium of hydrogen sulfide dissolved in alkanolamines solutions.

\section{Correlation of experimental data with thermodynamics model}

Hydrogen sulfide dissolved in aqueous alkanolamines is a system of electrolyte solution. Non-idealities of species in gas phase and liquid phase should be taken into account in the thermodynamic computation of multicomponent complex aqueous solution like $\mathrm{H}_{2} \mathrm{~S}-\mathrm{NG}$-(MEA-MDEA-PZ)water system. In this work, the Soave-Redlich-Kwong (SRK) equation of state [20] is used to account for the nonideality of gas phase, and the electrolyte-NRTL equation $[21,22]$ is adopted to describe that of the liquid phase. Herein, a brief description is made as follows.

\section{Chemical equilibrium relationship of species in the liquid aqueous solution}

The chemical equilibrium relationship of the species in the liquid phase can be written in the form of chemical dissociation $[3,23,24]$ as follows.

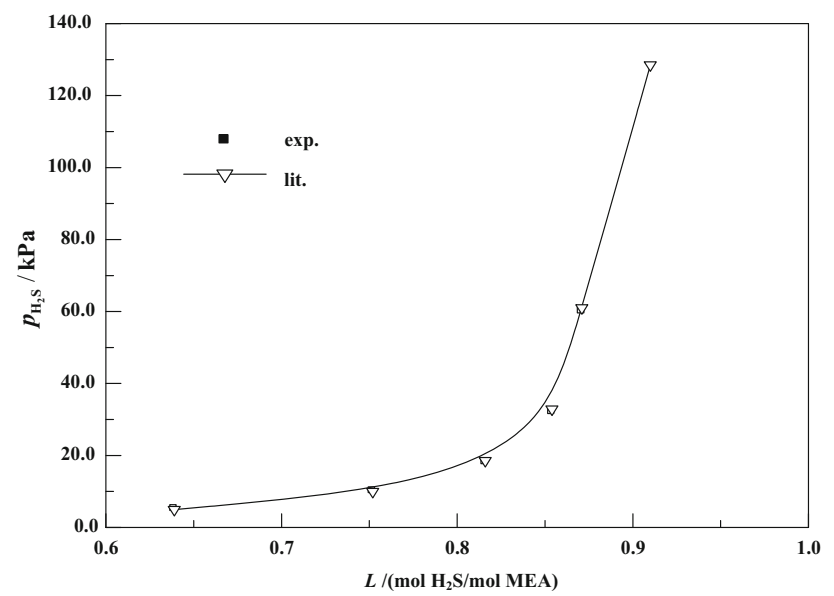

Fig. 2 The partial pressure of $\mathrm{H}_{2} \mathrm{~S}$ gas dissolved in $2.5 \mathrm{~mol} / \mathrm{L}$ MEA aqueous solution compared with literature data at $313.15 \mathrm{~K}$ and atmosphere pressure
$2 \mathrm{H}_{2} \mathrm{O} \stackrel{K_{W}}{\rightleftharpoons} \mathrm{H}_{3} \mathrm{O}^{+}+\mathrm{OH}^{-}$

$\mathrm{H}_{2} \mathrm{~S}+\mathrm{H}_{2} \mathrm{O} \stackrel{K_{1}}{\rightleftharpoons} \mathrm{H}_{3} \mathrm{O}^{+}+\mathrm{HS}^{-}$

$\mathrm{HS}^{-}+\mathrm{H}_{2} \mathrm{O} \stackrel{K_{2}}{\rightleftharpoons} \mathrm{H}_{3} \mathrm{O}^{+}+\mathrm{S}^{2-}$

$\mathrm{MEAH}^{+}+\mathrm{H}_{2} \mathrm{O} \stackrel{K_{3}}{\rightleftharpoons} \mathrm{H}_{3} \mathrm{O}^{+}+\mathrm{MEA}$

$\mathrm{MDEAH}^{+}+\mathrm{H}_{2} \mathrm{O} \stackrel{K_{4}}{\rightleftharpoons} \mathrm{H}_{3} \mathrm{O}^{+}+\mathrm{MDEA}$

$\mathrm{PZH}^{+}+\mathrm{H}_{2} \mathrm{O} \stackrel{K_{5}}{\rightleftharpoons} \mathrm{H}_{3} \mathrm{O}^{+}+P Z$

The chemical equilibrium constants from Eqs. (R1-R6) can be written as:

$K_{j}=\prod_{i} \hat{a}_{j i}^{v_{j i}} \quad(j=W, 1,2,3,4,5)$

where $K_{j}$ is the chemical equilibrium constant of the above Eqs. (R1-R6), $\hat{a}_{j i}$ and $v_{j i}$ are the activity and stoichiometric coefficient of component $i$ of the reaction $j$, respectively. The mass balance equations for the sulfur element and alkanolamine molecules can be expressed by

$n_{\mathrm{H}_{2} \mathrm{~S}}^{0}=n_{\mathrm{H}_{2} \mathrm{~S}}+n_{\mathrm{HS}^{-}}+n_{\mathrm{S}^{2-}}$

$n_{\mathrm{MEA}}^{0}=n_{\mathrm{MEA}}+n_{\mathrm{MEAH}^{+}}$

$n_{\mathrm{MDEA}}^{0}=n_{\mathrm{MDEA}}+n_{\mathrm{MDEAH}^{+}}$

$n_{\mathrm{PZ}}^{0}=n_{\mathrm{PZ}}+n_{\mathrm{PZH}^{+}}$

Another restriction is the condition of liquid phase electroneutrality, and can be written as

$\sum_{i} n_{i} z_{i}=0$

In Eq. (14), $n_{i}$ and $z_{i}$ are the molar quantity and charge number of ions (including ions of $\mathrm{H}_{3} \mathrm{O}^{+}, \mathrm{HS}^{-}, \mathrm{S}^{2-}$, $\mathrm{MEAH}^{+}, \mathrm{MDEAH}^{+}, \mathrm{PZH}^{+}, \mathrm{OH}^{+}$, etc. $)$.

The relationship of equilibrium constant for Eq. (9) and Henry's constant of hydrogen sulfide with temperature can be expressed in Eq. (15), and the parameters are listed in Table 1.

$\ln K_{j}$ or $\ln H_{\mathrm{H}_{2} \mathrm{~S}}^{p}=A_{1}+A_{2} / T+A_{3} \ln T+A_{4} T$.

\section{Gas-liquid equilibria for molecules}

The Henry's Law is adopted to express the gas-liquid equilibrium of $\mathrm{H}_{2} \mathrm{~S}$ :

$p y_{\mathrm{H}_{2} \mathrm{~S}} \underset{\mathrm{H}_{2} \mathrm{~S}}{\hat{\varphi}}=\gamma_{\mathrm{H}_{2} \mathrm{~S}}^{*} x_{\mathrm{H}_{2} \mathrm{~S}} H_{\mathrm{H}_{2} \mathrm{~S}}^{\infty} \exp \left[\frac{v_{\mathrm{H}_{2} \mathrm{~S}}^{\infty}\left(p-p^{\emptyset}\right)}{R T}\right]$

where $y_{\mathrm{H}_{2} \mathrm{~S}}, x_{\mathrm{H}_{2} \mathrm{~S}}$ are the molar fraction of hydrogen sulfide in gas phase and liquid phase. $\hat{\varphi}_{\mathrm{H}_{2} \mathrm{~S}}, \gamma_{\mathrm{H}_{2} \mathrm{~S}}^{*}$ are the fugacity 
Table 1 The relationship of equilibrium constant for Eq. (9) and $\mathrm{H}_{2} \mathrm{~S}$ Henry's constant with temperature

\begin{tabular}{lccccc}
\hline Equation & $A_{1}$ & $A_{2}$ & $A_{3}$ & $A_{4}$ & References \\
\hline \multicolumn{2}{l}{ Equilibrium constants } & & & & \\
R1 & 132.9 & -13446.0 & -22.48 & 0 & {$[22]$} \\
R2 & 214.6 & -12995.4 & -33.55 & 0 & {$[22]$} \\
R3 & -32.0 & -3338.0 & 0 & 0 & {$[22]$} \\
R4 & 2.1211 & -8189.38 & 0 & -0.007484 & {$[22]$} \\
R5 & -56.2 & -4044.8 & 7.848 & 0 & {$[3]$} \\
R6 & 4.964 & -9714.2 & 0 & 0 & {$[25]$} \\
Henry's constant & & & & & {$[22]$} \\
H & 358.138 & -133236.8 & -55.0511 & 0.059565 & \\
\hline
\end{tabular}

Table 2 Dielectric constants for MEA, MDEA, PZ and water

\begin{tabular}{lll}
\hline Solvent component & Equation & References \\
\hline MEA & $D=36.76+14836[1 / T(\mathrm{~K})-1 / 273.15]$ & {$[22]$} \\
MDEA & $D=24.74+8989.3[1 / T(\mathrm{~K})-1 / 273.15]$ & {$[23]$} \\
$\mathrm{PZ}$ & $D=4.719-1530[1 / T(\mathrm{~K})-1 / 273.15]$ & {$[29]$} \\
$\mathrm{H}_{2} \mathrm{O}$ & $D=78.65+31989[1 / T(\mathrm{~K})-1 / 273.15]$ & {$[23]$} \\
\hline
\end{tabular}

The dielectric constant of PZ is calculated as the method described in reference 29

\begin{tabular}{lccc}
\hline$\tau_{i j}, \tau_{j i}$ & $A$ & $B$ & References \\
\hline $\mathrm{H}_{2} \mathrm{O}-\mathrm{MDEA}$ & 8.5092 & -1573.9 & {$[23]$} \\
$\mathrm{MDEA}-\mathrm{H}_{2} \mathrm{O}$ & -1.7141 & -261.85 & {$[23]$} \\
$\mathrm{H}_{2} \mathrm{O}-\mathrm{PZ}$ & 3.66 & -310 & $\mathrm{a}$ \\
$\mathrm{PZ}-\mathrm{H}_{2} \mathrm{O}$ & 6.46 & -2648 & $\mathrm{a}$ \\
$\mathrm{H}_{2} \mathrm{O}-\mathrm{MEA}$ & 1.674 & 0 & {$[23]$} \\
$\mathrm{MEA}-\mathrm{H}_{2} \mathrm{O}$ & 0 & -649.75 & {$[23]$} \\
$\mathrm{H}_{2} \mathrm{O}-\mathrm{H}_{2} \mathrm{~S}$ & -3.674 & 1155.9 & {$[23]$} \\
$\mathrm{H}_{2} \mathrm{~S}-\mathrm{H}_{2} \mathrm{O}$ & -3.674 & 1155.9 & {$[23]$} \\
$\mathrm{H}_{2} \mathrm{O}-\mathrm{MEAH}^{+}, \mathrm{HS}^{-}$ & 6.844 & 501.83 & {$[23]$} \\
$\mathrm{MEAH}^{+}, \mathrm{HS}^{-}-\mathrm{H}_{2} \mathrm{O}$ & -3.560 & -197.12 & {$[23]$} \\
$\mathrm{H}_{2} \mathrm{O}-\mathrm{MDEAH}^{+}, \mathrm{HS}^{-}$ & 3.735 & 1036.04 & {$[23]$} \\
$\mathrm{MDEAH}^{+}, \mathrm{HS}^{-}-\mathrm{H}_{2} \mathrm{O}$ & -3.255 & 0 & $\mathrm{a}$ \\
$\mathrm{PZH}^{+}, \mathrm{HS}^{-}-\mathrm{H}_{2} \mathrm{O}$ & -3.79 & 0.98 & $\mathrm{a}$ \\
$\mathrm{H}_{2} \mathrm{O}-\mathrm{PZH}^{+}, \mathrm{HS}^{-}$ & 9.07 & 0 & \\
\hline
\end{tabular}

${ }^{a}$ The parameters are fitted as the method described in reference 14
Table 3 Binary interaction parameters used in the electrolyte-NRTL model $\left(\tau_{i j}=A+B / T\right)$ coefficient and activity factor of component $i$ in gas phase and liquid phase, respectively. $p_{i}^{\mathrm{s}}, v_{i}$ are the saturated gas pressure and molar volume of component $i$ under the equilibrium temperature $T$.

\section{Activity coefficient of component $i$}

The electrolyte-NRTL equation [25], which is composed of three contributions of excess Gibbs free energy counted by the Pitzer long-range interaction (PDH), corrected Born term (Born) and short-range solvation effect (NTRL), is used to calculate the activity coefficient of liquid phase 
Table 4 The molecular properties of pure components

\begin{tabular}{lccrcc}
\hline Component & $\begin{array}{l}\text { Molecular } \\
\text { weight }\end{array}$ & $T_{\mathrm{c}} / \mathrm{K}$ & $p_{\mathrm{c}} / \mathrm{kPa}$ & \multicolumn{1}{l}{$\begin{array}{l}V_{\mathrm{c}} / \\
\left(\mathrm{m}^{3} / \mathrm{kmol}\right)\end{array}$} & $Z_{\mathrm{c}}$ \\
\hline $\mathrm{H}_{2} \mathrm{~S}$ & 34.08 & 373.2 & 8936.9 & 0.0986 & 0.284 \\
$\mathrm{H}_{2} \mathrm{O}$ & 18.02 & 647.3 & 22090.0 & 0.0568 & 0.233 \\
$\mathrm{MEA}$ & 61.08 & 638.0 & 6870.0 & 0.2250 & 0.291 \\
$\mathrm{MDEA}$ & 119.16 & 677.8 & 3876.1 & 0.3932 & 0.192 \\
$\mathrm{PZ}$ & 86.14 & 364.85 & 5603.3 & 310.00 & 0.320 \\
\hline
\end{tabular}

components. For similar weak electrolyte solutions, this model had been widely used to correlate the gas-liquid equilibrium in literatures [16, 22, 26-28]. The parameters, including relevant coefficients and interaction parameters in the model could be also obtained in the literatures. Table 2 lists the dielectric constant for solvent components, like MEA, MDEA, PZ and water. Table 3 collects the binary interaction parameters of components, which are used to calculate the activity coefficient of components by the electrolyte-NRTL model.

\section{Fugacity coefficient for component $i$}

The fugacity coefficients of components in the gas phase are calculated by the SRK equation of state. Table 4 lists the molecular properties of pure components of this gasliquid equilibrium [19], which are used in the calculation with SRK equation of state.

\section{Calculation procedure}

The activity coefficient of components for liquid phase and fugacity coefficient for gas phase can be calculated by the electrolyte-NRTL equation and SRK equation of state, respectively. The total pressure for the equilibrated system can be calculated by the following Eq. (18), which ignored the partial pressure of other components excluding $\mathrm{H}_{2} \mathrm{~S}$, solvent components and $\mathrm{CH}_{4}$ in the gas phase.

$$
\begin{aligned}
p= & \frac{\gamma_{\mathrm{H}_{2} \mathrm{~S}}^{*} x_{\mathrm{H}_{2} \mathrm{~S}} H_{\mathrm{H}_{2} \mathrm{~S}}^{\infty}}{\hat{\varphi}_{\mathrm{H}_{2} \mathrm{~S}}} \exp \left[\frac{v_{\mathrm{H}_{2} \mathrm{~S}}^{\infty}\left(p-p^{\emptyset}\right)}{R T}\right] \\
& +\sum_{i} \frac{\gamma_{i} x_{i} p_{i}^{\mathrm{s}}}{\hat{\varphi}_{i}} \exp \left[\frac{v_{i}\left(p-p_{i}^{\mathrm{s}}\right)}{R T}\right]+p_{\mathrm{CH}_{4}}
\end{aligned}
$$

The Bubble point method was adopted to calculate the gasliquid equilibria. Ordinarily, the known variables are the temperature $T$, concentration of hydrogen sulfide in the liquid phase $x_{\mathrm{H}_{2} \mathrm{~S}}$, initial molar quantity of solvent components, like MEA, MDEA, PZ and water, by solving the equation set of Eqs. (9-14), as well as Eq. (16) and Eq. (17), the total pressure of the equilibrated system $p_{\mathrm{cal}}$. and molar fraction of hydrogen sulfide $y_{\mathrm{H}_{2} \mathrm{~S}}$ can be evaluated by the

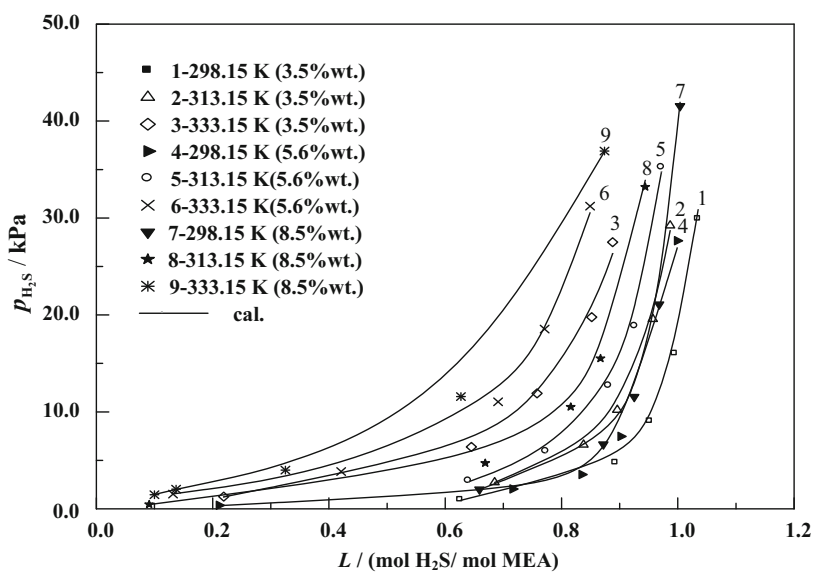

Fig. 3 Comparison of the calculated $\mathrm{H}_{2} \mathrm{~S}$ partial pressure with experimental data at various isotherms and different concentrations of aqueous MEA solution

objective function approaching to minimum, i.e., $O B J=$ $\sqrt{\left(\sum_{j}\left(p_{\text {cal. }}-p_{\text {exp. }}\right)^{2}+\sum_{j}\left(y_{\mathrm{H}_{2} \mathrm{~S}, \text { cal. }}-y_{\mathrm{H}_{2} \mathrm{~S}, \exp .}\right)^{2}\right) / 2 N} \rightarrow \min$. where $N$ is the number of experimental points.

\section{Results and discussions}

\section{Experimental data of $\mathrm{H}_{2} \mathrm{~S}$ dissolved in a single alkanolamine aqueous solution}

Comparisons of the calculated partial pressures of hydrogen sulfide with the experimental data, which is dissolved in a different aqueous MEA solution at absorption isotherms of $298.15,313.15$ and $333.15 \mathrm{~K}$, are shown in Fig. 3. As seen from Fig. 3, with the increasing of $\mathrm{H}_{2} \mathrm{~S}$ loading in liquid phase, the partial pressure of $\mathrm{H}_{2} \mathrm{~S}$ in the gas phase increases under any an isotherm. While, the increment of $\mathrm{H}_{2} \mathrm{~S}$ partial pressure shows a small value under the condition of relatively lesser $\mathrm{H}_{2} \mathrm{~S}$ loading along an isotherm at first; then it sharply increases at the higher $\mathrm{H}_{2} \mathrm{~S}$ loading along the same isotherm. For an example, at the isotherm of aqueous $\mathrm{H}_{2} \mathrm{~S}-\mathrm{NG}-8.5 \%$ wt. MEA-water solution at $333.15 \mathrm{~K}$ (Line 9 in Fig. 3), the $\mathrm{H}_{2} \mathrm{~S}$ partial pressure increases from 1.462 to $3.997 \mathrm{kPa}$ by the difference value of $2.535 \mathrm{kPa}$ when $\mathrm{H}_{2} \mathrm{~S}$ loading in the aqueous solution changes from 0.100 to 0.325 (the difference value of 0.225$)$. But it increases rapidly from 11.578 to $36.914 \mathrm{kPa}$ when $\mathrm{H}_{2} \mathrm{~S}$ loading varies from 0.627 to 0.874 (the difference value of 0.247 ). The reason is that the desulfuration of $\mathrm{H}_{2} \mathrm{~S}$ by aqueous alkanolamine solutions has the features of both chemical absorption and physical absorption. The chemical reaction of hydrogen sulfide with MEA is to be equilibrium with a larger $\mathrm{H}_{2} \mathrm{~S}$ loading in 


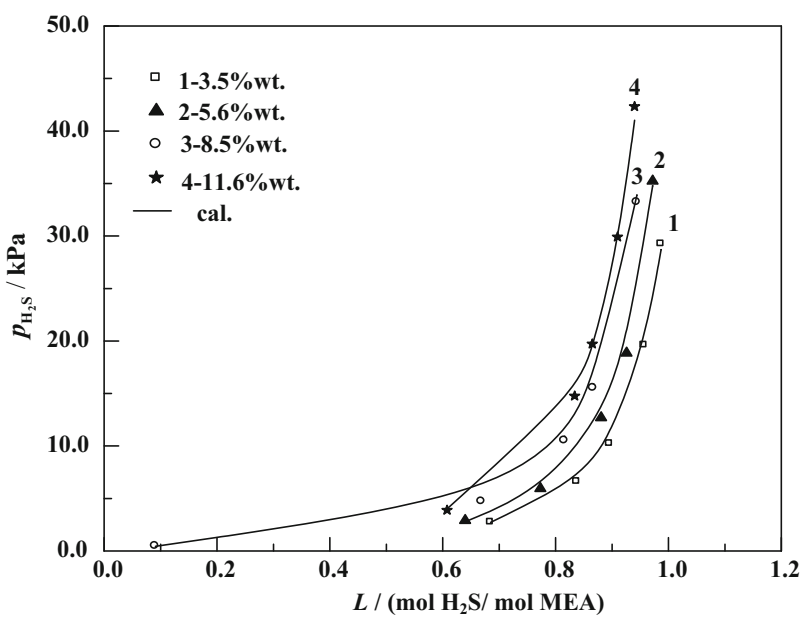

Fig. 4 Comparison of the calculated $\mathrm{H}_{2} \mathrm{~S}$ partial pressure with experimental value at $333.15 \mathrm{~K}$ under different isoconcentration of aqueous MEA solution

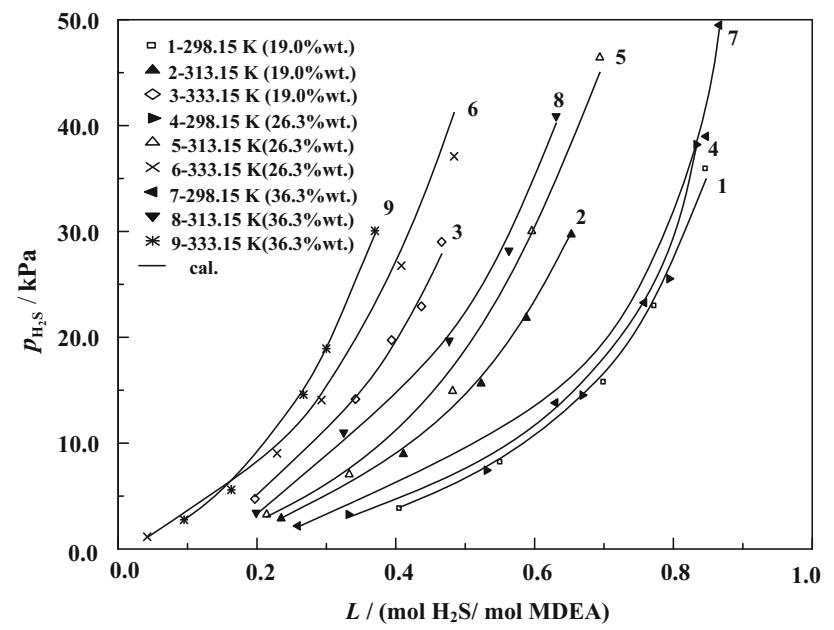

Fig. 5 Comparison of the calculated $\mathrm{H}_{2} \mathrm{~S}$ partial pressure with experimental data at various isotherms and different concentrations of aqueous MDEA solution

liquid. And then the chemical absorption is transferred into physical absorption, so the $\mathrm{H}_{2} \mathrm{~S}$ partial pressure in the gas phase increases theatrically sharply at the larger $\mathrm{H}_{2} \mathrm{~S}$ loading.

Meanwhile, the $\mathrm{H}_{2} \mathrm{~S}$ partial pressure increases with the rising of absorption temperature at the conditions of a constant $\mathrm{H}_{2} \mathrm{~S}$ loading and the same component concentrations of the aqueous absorption solution. The $\mathrm{H}_{2} \mathrm{~S}$ loading in liquid phase decreases with the rising of absorption temperature under the same $\mathrm{H}_{2} \mathrm{~S}$ partial pressure and the same component concentrations. These behaviors are the universal phenomena of the influence of temperature on the $\mathrm{H}_{2} \mathrm{~S}$ partial pressure under the conditions of the constant $\mathrm{H}_{2} \mathrm{~S}$ loading and the same component concentrations.

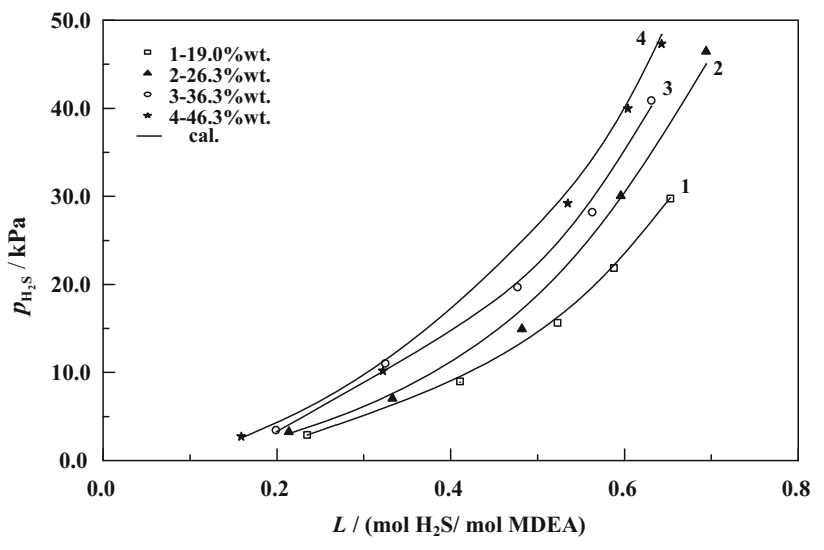

Fig. 6 Comparison of the calculated $\mathrm{H}_{2} \mathrm{~S}$ partial pressure with experimental value at $333.15 \mathrm{~K}$ under different isoconcentration of aqueous MDEA solution

The average relative errors of total pressure and $\mathrm{H}_{2} \mathrm{~S}$ partial pressure between the theoretical values and the experimental data for the system of aqueous $\mathrm{H}_{2} \mathrm{~S}-\mathrm{NG}$ MEA-water are 3.01 and $3.26 \%$, respectively.

The $\mathrm{H}_{2} \mathrm{~S}$ partial pressure calculated by the electrolyteNRTL model is compared with the experimental value at $333.15 \mathrm{~K}$ under different isoconcentration of aqueous MEA solution as shown in Fig. 4. The results show that the calculated values are in good consistent with the experimental ones. The $\mathrm{H}_{2} \mathrm{~S}$ partial pressure increases with the higher concentration of aqueous MEA solution at a constant $\mathrm{H}_{2} \mathrm{~S}$ loading; the loading of $\mathrm{H}_{2} \mathrm{~S}$ in the liquid phase decreases with higher concentration of the aqueous MEA solution at a constant $\mathrm{H}_{2} \mathrm{~S}$ partial pressure.

The relationship of $\mathrm{H}_{2} \mathrm{~S}$ partial pressure with $\mathrm{H}_{2} \mathrm{~S}$ loading in aqueous solution of the system consisting of $\mathrm{H}_{2} \mathrm{~S}$-NG-MDEA-water is presented in Figs. 5 and 6. These two Figures have very similar features as the aqueous MEA solutions shown in Figs. 3 and 4, respectively. And the calculated results are also in agreement with the experimental data. Compared two $\mathrm{H}_{2} \mathrm{~S}$ absorption isotherms lines, for instance numbered as line 1, shown in Figs. 3 and 4, the $\mathrm{H}_{2} \mathrm{~S}$ loading is 1.02 in Fig. 3 under the condition of $20.0 \mathrm{kPa} \mathrm{H}_{2} \mathrm{~S}$ partial pressure and $298.15 \mathrm{~K}$, which is larger than that of 0.742 in Fig. 4 at the same conditions. The result shows that the desulfuration ability of aqueous MEA solution is stronger than that of MDEA, although the concentration of aqueous MDEA is higher than that of MEA solution.

The average relative errors of total pressure and $\mathrm{H}_{2} \mathrm{~S}$ partial pressure between the calculated values and the experimental data for the system of aqueous $\mathrm{H}_{2} \mathrm{~S}-\mathrm{NG}$ MDEA-water are 3.46 and $2.91 \%$, respectively. 


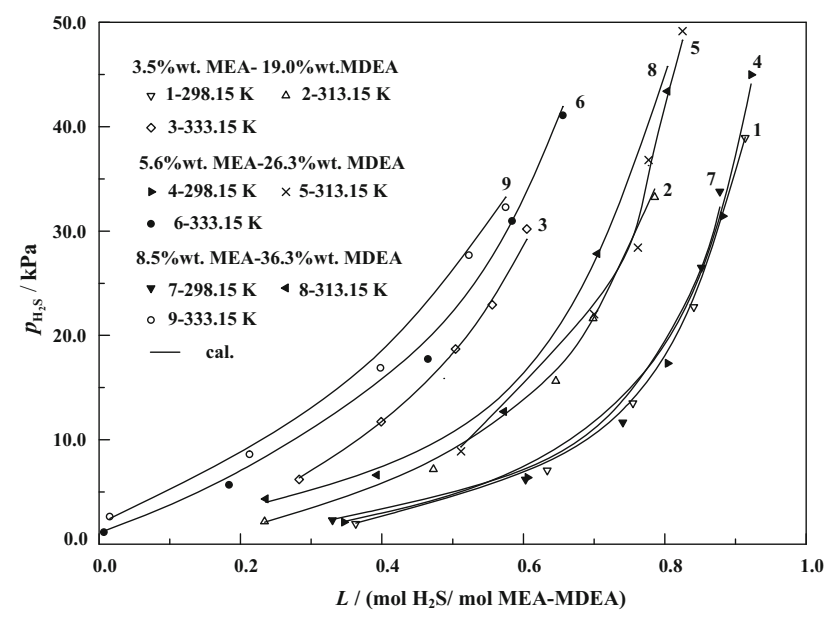

Fig. 7 Comparison of the calculated $\mathrm{H}_{2} \mathrm{~S}$ partial pressure with experimental data at different isotherms and different equi-composition of the mixed aqueous MEA-MDEA solution

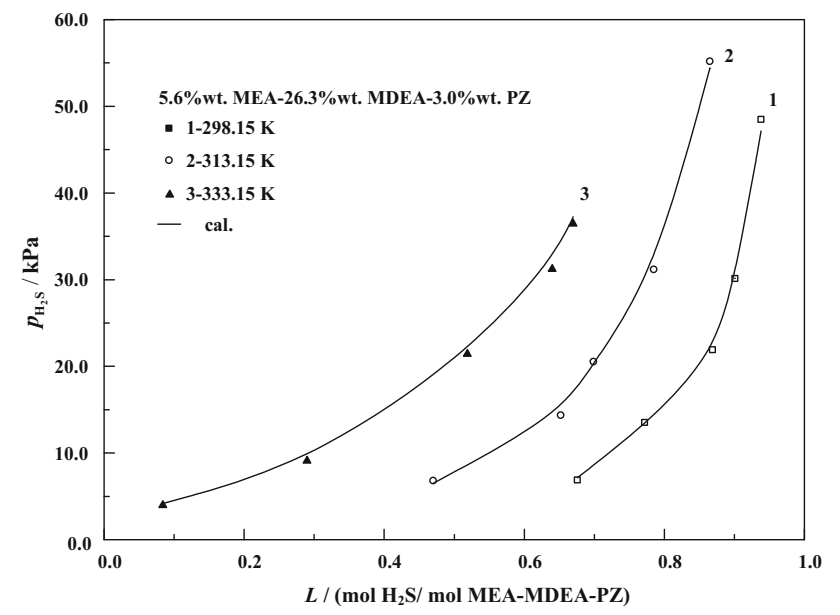

Fig. 8 Comparison of calculated $\mathrm{H}_{2} \mathrm{~S}$ partial pressure with experimental data at different isotherms for the aqueous 5.6\%wt. MEA$26.3 \%$ wt. MDEA-3.0 \%wt. PZ solution

\section{Influence of MEA and piperazine added into the MDEA aqueous solutions}

Comparison of calculated $\mathrm{H}_{2} \mathrm{~S}$ partial pressure with the experimental data of $\mathrm{H}_{2} \mathrm{~S}-\mathrm{NG}$-(MEA-MDEA)-water system at different isotherms and different equi-compositions is shown in Fig. 7. The blends of MEA and MDEA for $\mathrm{H}_{2} \mathrm{~S}$ absorption have the similar performance with the signal MEA or MDEA. It also can be seen in Fig. 7 that the total content of the mixed aqueous MEA-MDEA solution has little effect on the relationships between $\mathrm{H}_{2} \mathrm{~S}$ loading and $\mathrm{H}_{2} \mathrm{~S}$ partial pressure at lower temperatures, i.e., 298.15 and $313.15 \mathrm{~K}$, but has significantly influence at higher temperature, i.e. $333.15 \mathrm{~K}$. And the deviations become significant at high temperatures for the MEA-MDEA

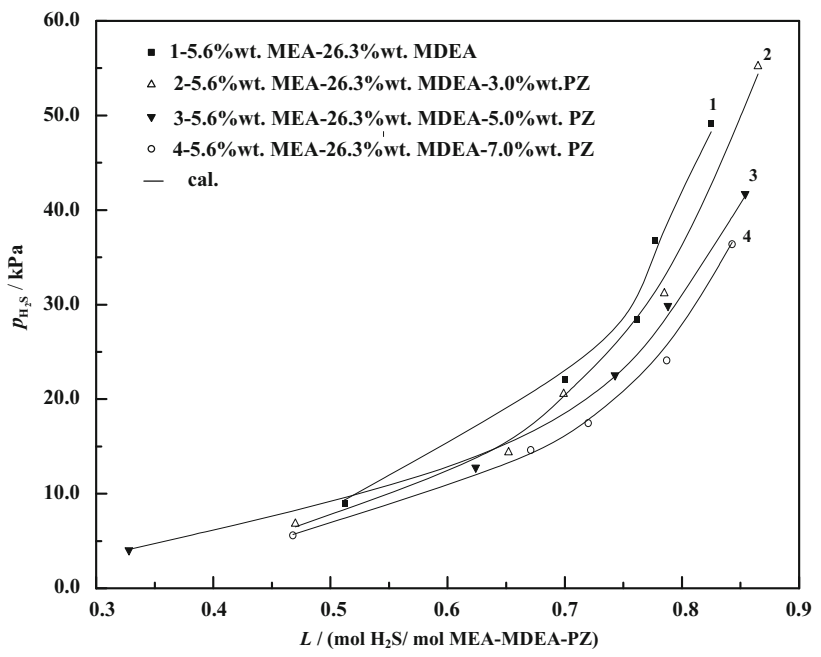

Fig. 9 Comparisons of calculated and experimental data of $\mathrm{H}_{2} \mathrm{~S}$ partial pressure for the mixed aqueous (MEA-MDEA-PZ) solutions with different PZ content at $313.15 \mathrm{~K}$

solutions. The reason is that the MEA-MDEA solutions have a higher absorption capacity for $\mathrm{H}_{2} \mathrm{~S}$, and the influences of total content of MEA-MDEA become more and more important with the increasing of temperature.

The average relative errors of total pressure and $\mathrm{H}_{2} \mathrm{~S}$ partial pressure between the calculated values and the experimental data for the system of aqueous $\mathrm{H}_{2} \mathrm{~S}-\mathrm{NG}$ (MEA-MDEA)-water are 3.12 and $3.00 \%$, respectively.

By comparing $\mathrm{H}_{2} \mathrm{~S}$ loading in liquid phase under a certain $\mathrm{H}_{2} \mathrm{~S}$ partial pressure and absorption temperature shown in Figs. 3, 5 and 7, the size order of $\mathrm{H}_{2} \mathrm{~S}$ absorption ability for the three systems, i.e. MEA, MDEA and the mixed MEAMDEA, is MEA > (MEA-MDEA) > MDEA, which indicates that the addition of MEA into aqueous MDEA solution can improve the desulfuration ability of MDEA.

The relationship of the $\mathrm{H}_{2} \mathrm{~S}$ partial pressure with its loading in the liquid phase of the mixed aqueous (MEAMDEA-PZ) solutions containing PZ is shown in Fig. 8. As discussed above, the $\mathrm{H}_{2} \mathrm{~S}$ partial pressure increases with the higher of $\mathrm{H}_{2} \mathrm{~S}$ loading along the isotherms shown in Fig. 8 . The addition of the PZ into the mixed aqueous MEA-MDEA solution is beneficial for increasing its ability of desulfuration. The size order of $\mathrm{H}_{2} \mathrm{~S}$ absorption ability for the above four systems, i.e. MEA, MDEA, mixed (MEA-MDEA), and mixed (MEA-MDEA-PZ), is MEA $>$ (MEA-MDEAPZ) $>($ MEA-MDEA) $>$ MDEA, which indicates that the addition of MEA and PZ into aqueous MDEA solutions can well enhance the desulfuration ability of MDEA.

The influence of $\mathrm{PZ}$ content on the relationship of $\mathrm{H}_{2} \mathrm{~S}$ partial with its loading in the liquid phase along the four iso-concentration curves of component MEA and MDEA at $313.15 \mathrm{~K}$ is shown in Fig. 9. As seen in Fig. 9, the more content of $\mathrm{PZ}$, the greater $\mathrm{H}_{2} \mathrm{~S}$ loading in the liquid phase 


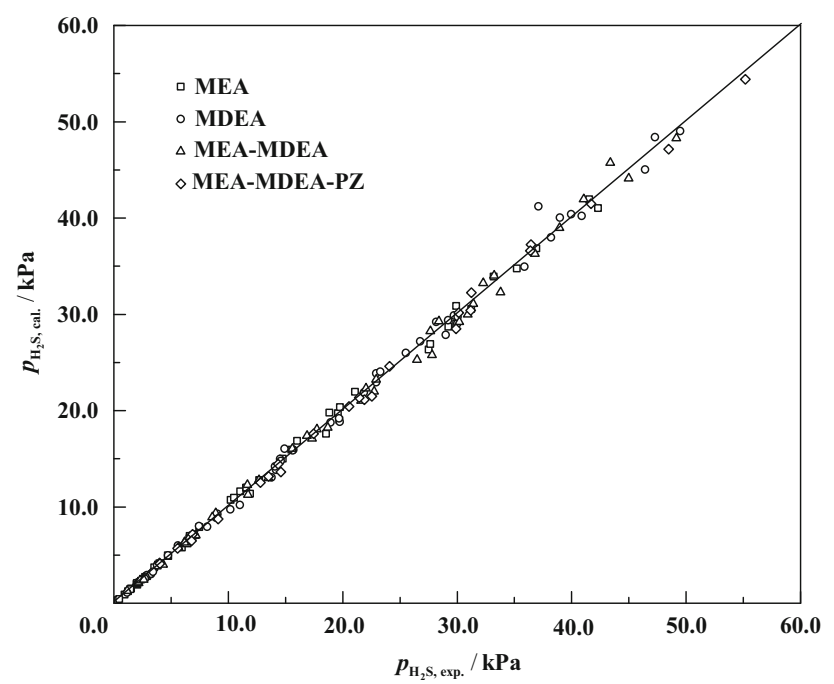

Fig. 10 Comparison of $\mathrm{H}_{2} \mathrm{~S}$ partial pressure calculated by the model with experimental data

under the condition of a constant $\mathrm{H}_{2} \mathrm{~S}$ partial pressure. And the more quantity of $\mathrm{PZ}$ containing, the lower $\mathrm{H}_{2} \mathrm{~S}$ partial pressure under the condition of a constant $\mathrm{H}_{2} \mathrm{~S}$ loading in the liquid phase. Especially, the four curves tend to be closer at the low $\mathrm{H}_{2} \mathrm{~S}$ loadings about from 0.3 to 0.6. The reason is that almost identical desulfuration ability for these four aqueous absorption systems at this range.

The average relative errors of total pressure and $\mathrm{H}_{2} \mathrm{~S}$ partial pressure between the calculated values and the experimental data for the system of aqueous $\mathrm{H}_{2} \mathrm{~S}-\mathrm{NG}$ (MEA-MDEA-PZ)-water are 3.47 and $3.08 \%$, respectively.

\section{Comparison of calculated results by model and experimental data}

The comparison of $\mathrm{H}_{2} \mathrm{~S}$ partial pressure calculated by the SRK equation of state and electrolyte-NRTL model with the experimental data for the four systems above is shown in Fig. 10. The overall average relative errors of total pressure and $\mathrm{H}_{2} \mathrm{~S}$ partial pressure are 3.30 and $3.07 \%$, respectively. It shows that the calculated results are very well consistent with the experimental data, and the selected models can well describe the non-idealities of the gas phase and the liquid phase containing aqueous weak electrolytes of hydrogen sulfide dissolved in a kind of mixed alkanolamine solution.

\section{Conclusions}

The gas-liquid equilibrium data for desulfuration of natural gas (NG) by using a mixed aqueous alkanolamine solution was investigated and the results were used for evaluating their ability of removing hydrogen sulfide. The apparatus was a glass-jacketed gas absorption cell with a doubledrive impeller device. Four gas-liquid equilibria systems, i.e. $\mathrm{H}_{2} \mathrm{~S}$-NG-MEA-water, $\mathrm{H}_{2} \mathrm{~S}$-NG-MDEA-water, $\mathrm{H}_{2} \mathrm{~S}$ NG-(MEA- MDEA)- water, $\mathrm{H}_{2} \mathrm{~S}$-NG-(MEA-MDEA-PZ)water at the temperature ranging from 298.15 to $313.15 \mathrm{~K}$ were experimentally investigated in this work. The equilibrium data were correlated with SRK equation of state and electrolyte-NRTL activity coefficient model, which describe the non-idealities of the gas phase and the aqueous weak electrolyte solution. The results show that the $\mathrm{H}_{2} \mathrm{~S}$ partial pressure increases with the higher of $\mathrm{H}_{2} \mathrm{~S}$ loading along an isotherm. The quantity of $\mathrm{H}_{2} \mathrm{~S}$ loading in the aqueous phase decreases when the temperature increases under the condition of constant $\mathrm{H}_{2} \mathrm{~S}$ partial pressure. The addition of MEA and PZ is beneficial for improving the desulfuration ability of MDEA. The size order of $\mathrm{H}_{2} \mathrm{~S}$ absorption ability for the four systems, i.e. MEA, MDEA, the mixed (MEA-MDEA), and the mixed (MEA-MDEAPZ), is MEA $>$ (MEA-MDEA-PZ) $>$ (MEA-MDEA) $>$ MDEA. The four sets of gas-liquid equilibria data can be well correlated with the SRK equation of state and electrolyte-NRTL activity coefficient model. The overall average relative errors of total pressure and $\mathrm{H}_{2} \mathrm{~S}$ partial pressure between the calculated and experimental results of the above four absorption systems are 3.30 and $3.07 \%$, respectively. The experimental and calculated results are very useful for desulfuration and purification process of natural gas or other industrial gases.

Open Access This article is distributed under the terms of the Creative Commons Attribution 4.0 International License (http://crea tivecommons.org/licenses/by/4.0/), which permits unrestricted use, distribution, and reproduction in any medium, provided you give appropriate credit to the original author(s) and the source, provide a link to the Creative Commons license, and indicate if changes were made.

\section{References}

1. Lemoine B, Li YG, Cadours R, Bouallou C, Richon D (2000) Partial vapor pressure of $\mathrm{CO}_{2}$ and $\mathrm{H}_{2} \mathrm{~S}$ over aqueous methyldiethanolamine solutions. Fluid Phase Equilib 172:261-277

2. Haghtalab A, Dehghani Tafti M (2007) Electrolyte UNIQUACNRF model to study the solubility of acid gases in alkanolamines. Ind Eng Chem Res 46:6053-6060

3. Vrachnos A, Kontogeorgis G, Voutsas E (2006) Thermodynamic modeling of acidic gas solubility in aqueous solutions of MEA, MDEA and MEA-MDEA blends[J]. Ind Eng Chem Res 245:5148-5154

4. Dash SK, Samanta AN, Bandyopadhyay SS (2011) Solubility of carbon dioxide in aqueous solution of 2-amino-2-methyl-1-propanol and piperazine. Fluid Phase Equilib 307:166-174

5. Haghtalab A, Izadi A (2014) Simultaneous measurement solubility of carbon dioxide + hydrogen sulfide into aqueous blends of alkanolamines at high pressure. Fluid Phase Equilib 375:181-190

6. Chakravarty T, Phukan UK, Weiland RH (1985) Reaction of acid gases with mixtures of amines. Chem Eng Prog 81:32-36 
7. Bishnoi S, Rochelle GT (2000) Absorption of carbon dioxide into aqueous piperazine: reaction kinetics, mass transfer and solubility. Chem Eng Sci 55:5531-5543

8. Sun WC, Yong CB, Li MH (2005) Kinetics of the absorption of carbon dioxide into mixed aqueous solutions of 2-amino-2methyl-1-propanol and piperazine. Chem Eng Sci 60:503-516

9. Bishnoi S, Rochelle GT (2002) Absorption of carbon dioxide in aqueous piperazine/methyldiethanolamine. AIChE J 48:2788-2799

10. Xu X, Cai ZY, Liang K (2010) A study on flue gas desulfurization using aqueous piperazine. Environ Chem 29:450-454 (in Chinese)

11. Lee JI, Otto FD, Mather AE (1976) Equilibrium in hydrogen sulfide-monoethanolamine-water system. J Chem Eng Data 21:207-208

12. Isaacs EE, Otto FD, Mather AE (1980) Solubility of mixtures of hydrogen sulfide and carbon dioxide in a monoethanolamine solution at low partial pressures. J Chem Eng Data 25:118-120

13. Jou FY, Mather AE, Otto FD (1982) Solubility of $\mathrm{H}_{2} \mathrm{~S}$ and $\mathrm{CO}_{2}$ in aqueous methyldiethanolamine solutions. Ind Eng Chem Process Des Dev 21:539-544

14. Jou FY, Carroll JJ, Mather AE, Otto FD (1993) The solubility of carbon dioxide and hydrogen sulfide in a $35 \mathrm{wt} \%$ aqueous solution of methyldiethanolamine. Can J Chem Eng 71:264-268

15. Jou FY, Carroll JJ, Mather AE, Otto FD (1993) Solubility of mixtures of hydrogen sulfide and carbon dioxide in aqueous $\mathrm{N}$ methldiethanolmine solutions. J Chem Eng Data 38:75-77

16. Kuranov G, Rumpf B, Smirnova NA, Maurer G (1996) Solubility of single gases carbon dioxide and hydrogen sulfide in aqueous solutions of $\mathrm{N}$-methyldiethanolamine in the temperature range $313-413 \mathrm{~K}$ at pressure up to $5 \mathrm{MPa}$. Ind Eng Chem Res 35:1959-1966

17. Kamps ÁP-S, Balaban A, Jödecke M, Kuranov G, Smirnova NA, Maurer G (2001) Solubility of single gases carbon dioxide and hydrogen sulfide in aqueous solutions of $N$-methyldiethanolamine at temperatures from 313 to $393 \mathrm{~K}$ and pressures up to $7.6 \mathrm{MPa}$ : new experimental data and model extension. Ind Eng Chem Res 40:696-706

18. Li M-H, Shen K-P (1993) Solubility of hydrogen sulfide in aqueous mixtures of monoethanolamine with $\mathrm{N}$-methldiethanolamine. J Chem Eng Data 38:105-108
19. Perry RH, Green DW, Maloney JO (1997) Perry's chemical engineers' handbook, 7th edn. McGraw-hill, New York

20. Soave G (1972) Equilibrium constants from a modified RedlichKwong equation of state. Chem Eng Sci 27:1197-1203

21. Austgen DM, Rochelle GT, Peng X, Chen CC (1989) Model of vapor-liquid equilibria for aqueous acid gas-alkanolamine systems using the Electrolyte-NRTL equation. Ind Eng Chem Res 28:1060-1073

22. Austgen DM, Rochelle GT, Chen CC (1991) Model of vaporliquid equilibria for aqueous acid gas-alkanolamine systems. 2 . Representation of hydrogen sulfide and carbon dioxide solubility in aqueous MDEA and carbon dioxide solubility in aqueous mixtures of MDEA with MEA or DEA. Ind Eng Chem Res 30:543-555

23. Li Y, Mather AE (1997) Correlation and prediction of the solubility of $\mathrm{CO}_{2}$ and $\mathrm{H}_{2} \mathrm{~S}$ in aqueous solutions of methyldiethanolamine. Ind Eng Chem Res 36:2760-2765

24. Bishnoi S, Rochelle GT (2002) Thermodynamics of piperazine/ methyldiethanolamine/water/carbon dioxide. Ind Eng Chem Res 41:604-612

25. Mock B, Evans LB, Chen CC (1986) Thermodynamic representation of phase equilibria of mixed-solvent electrolyte systems. AIChE J 32:1655-1664

26. Hetzer HB, Robinson RA, Bates RG (1968) Dissociation constants of piperazinium ion and related thermodynamic quantities from $0^{\circ}$ to $50^{\circ}$. J Phys Chem C 72:2081-2086

27. Vrachnos A, Voutsas E, Magoulas K, Lygeros A (2004) Thermodynamics of acid gas-MDEA-water systems. Ind Eng Chem Res 43:2798-2804

28. Masih HJ, Majid AA, Seyed SH, Medhi V, Naser SM (2005) Solubility of carbon dioxide in aqueous mixtures of $\mathrm{N}$ methyldiethanolamine + piperazine + sulfolane. J Chem Eng Data 50:583-586

29. Derks PWJ, Dijkstra HBS, Hogendoorn JA, Versteeg GF (2005) Solubility of carbon dioxide in aqueous piperazine solutions. AIChE J 51:2311-2327 